\title{
Investigational Medicinal Product Documentation
}

National Cancer Institute

\section{Source}

National Cancer Institute. Investigational Medicinal Product Documentation. NCI

Thesaurus. Code C115702.

Records pertaining to an investig ational product (IP). 